\title{
Review of Eight Pharmacoeconomic Studies of the Value of Biologic DMARDs (Adalimumab, Etanercept, and Infliximab) in the Management of Rheumatoid Arthritis
}

\author{
QUAN V. DOAN, PharmD; CHIUN-FANG CHIOU, PhD; and ROBERT W. DUBOIS, MD, PhD
}

\begin{abstract}
BACKGROUND: Treatment options for the management of rheumatoid arthritis (RA) have expanded from the traditional disease-modifying antirheumatic drugs (DMARDs) to include the biologic DMARDs that inhibit tumor necrosis factoralpha (TNF- $\alpha$ ).

OBJECTIVE: To assess the medical literature for studies of the economic value of biologic DMARDs, specifically the 3 TNF- $\alpha$ inhibitors (adalimumab, etanercept, and infliximab) used for the management of RA, compared with the traditional DMARDs such as sulfasalazine, antimalarials, penicillamine, gold, methotrexate, azathioprine, leflunomide, and cyclophosphamide.

METHODS: A comprehensive search of the MEDLINE and HealthSTAR databases was conducted to identify cost-efficacy, cost-effectiveness, or cost-utility studies published in the English language (from 1966 through November 2004). The search terms and/or MeSH (medical subject headings) titles were cost-benefit analysis, rheumatoid arthritis, antirheumatic agents, antineoplastic and immunosuppressive agents. Studies were critically reviewed and quality was assessed using the Quality of Health Economic Studies instrument. Most studies evaluated the use of biologics among RA patients resistant to DMARDs. Studies were assessed with regard to comparators evaluated, measures of efficacy, perspectives, model duration, treatment duration, and discount rate.
\end{abstract}

RESULTS: From 180 titles identified, 155 were excluded for the following reasons: 89 because they did not consider the drugs of interest, 15 because the population was not RA, 19 because of having the wrong drugs and population, 22 because they were review articles, and 10 because they were general articles. Twentyfive abstracts were accepted for further review. Of these, 13 abstracts were subsequently selected for full-text review. One of the authors identified a study not indexed in MEDLINE. Ultimately, 2 cost-effectiveness and 6 cost-utility studies were selected for this critical review. One study over 6 months reported that triple therapy with DMARDs (methotrexate-hydroxychloroquine-sulfasalazine) was cost effective for methotrexate-resistant patients, which is consistent with American College of Rheumatology (ACR) guidelines that support the use of triple therapy prior to biologics. The incremental cost-effectiveness ratio (ICER) was $\$ 1,500$ per patient to achieve an ACR20 response for this triple therapy compared with no second-line agent. Overall, biologic therapies cost considerably more than traditional DMARDs but produced more quality-adjusted life-years (QALYs). Despite differences in design and assumptions, published economic models consistently reported ICERs $<\$ 50,000$ per QALY gained for biologics compared with traditional DMARDs, although ICERs of $>\$ 100,000$ were reported from sensitivity analyses.

CONCLUSIONS: Clinical guidelines currently recommend the use of biologics as step therapy after failure of traditional DMARDs. Reported ICERs comparing biologics with traditional DMARDs are within a range that is comparable with other accepted medical interventions. The worth of the additional expenditure will ultimately be judged by formulary and policy decision makers because no maximum cost has been defined. Models can be used to inform decision makers, but they must be interpreted and applied carefully. More research is also needed to differentiate the relative economic value of the various biologic agents by therapeutic indication.

KEYWORDS: Cost-effectiveness, Cost-utility, Rheumatoid arthritis, Biologics, DMARDs, Anti-TNF- $\alpha$

J Manag Care Pharm. 2006;12(7):555-69
$\mathrm{R}$ heumatoid arthritis (RA) is a systemic chronic inflammatory condition that presents with joint swelling, tenderness and inflammation. The prevalence of RA in North America is estimated to be $0.5 \%-1.0 \%{ }^{1}$ As joint damage progresses over time, patients experience increasing levels of disability. Consequently, RA imposes a substantial economic burden on society. The direct and indirect medical costs for RA were estimated to be $\$ 26$ to $\$ 32$ billion per year in the United States in 1998 dollars. ${ }^{2}$

The American College of Rheumatology (ACR) established that the goals of managing RA are to prevent or control joint damage, prevent loss of function, and decrease pain. ${ }^{3}$ Treatment options for RA historically have included nonsteroidal antiinflammatory drugs, analgesics, corticosteroids, and traditional disease-modifying antirheumatic drugs (DMARDs). Traditional DMARDs include drugs such as sulfasalazine, antimalarials, penicillamine, gold, methotrexate, azathioprine, leflunomide, and cyclophosphamide. Disease activity is evaluated periodically, and the regimen is adjusted based on clinical response. ${ }^{3}$ The effectiveness of traditional DMARDs may decrease as the disease progresses or when patients experience adverse effects that require switching

Once patients fail at least 2 standard DMARD therapies, one of which includes methotrexate, they are potential candidates for biologic therapies per the recommendations of the British Society of Rheumatology (BSR) guidelines. ${ }^{4}$ Since the late 1990s, the most studied class in the drug armamentarium for RA is biologic DMARDs, which inhibit tumor necrosis factoralpha (TNF- $\alpha$ inhibitors; see Table 1). TNF- $\alpha$ is a cytokine present in the rheumatoid joints and is involved in the abnormal inflammatory and immune responses that occur with RA. Biologics can offer better clinical response compared with

\section{Authors}

QUAN V. DOAN, PharmD, is senior associate director and ROBERT W. DUBOIS, $\mathrm{MD}, \mathrm{PhD}$, is chief medical officer, Cerner LifeSciences, Beverly Hills, California; CHIUN-FANG CHIOU, PhD, is associate director, Global Health Economics, Amgen Inc., Thousand Oaks, California.

AUTHOR CORRESPONDENCE: Quan V. Doan, PharmD, Senior Associate Director, Cerner LifeSciences, 9100 Wilshire Blvd., Suite 605E, Beverly Hills, CA 90212. Tel: (310) 598-4456; Fax: (816) 936-1856; E-mail:qdoan@cerner.com

Copyright $\odot$ 2006, Academy of Managed Care Pharmacy. All rights reserved. 


\section{Review of Eight Pharmacoeconomic Studies of the Value of Biologic DMARDs (Adalimumab, Etanercept, and Infliximab) in the Management of Rheumatoid Arthritis}

\section{(TABLE 1 FDA-Approved Indications for TNF- $\alpha$ Inhibitors}

TNF- $\alpha$ Inhibitor $\quad$ FDA-Approved Indication

\begin{tabular}{l|l}
\hline Infliximab* & Rheumatoid arthritis:
\end{tabular}

- Infliximab, in combination with methotrexate, is indicated for reducing signs and symptoms, inhibiting the progression of structural damage, and improving physical function in patients with moderately to severely active rheumatoid arthritis.

Crohn's disease:

- Infliximab is indicated for reducing signs and symptoms and inducing and maintaining clinical remission in adult and pediatric patients with moderately to severely active Crohn's disease who have had an inadequate response to conventional therapy.

- Infliximab is indicated for reducing the number of draining enterocutaneous and rectovaginal fistulas and maintaining fistula closure in adult patients with fistulizing Crohn's disease.

Ankylosing spondylitis:

- Infliximab is indicated for reducing signs and symptoms in patients with active ankylosing spondylitis.

Psoriatic arthritis:

- Infliximab is indicated for reducing signs and symptoms of active arthritis in patients with psoriatic arthritis.

Ulcerative colitis:

- Infliximab is indicated for reducing signs and symptoms, achieving clinical remission and mucosal healing, and eliminating corticosteroid use in patients with moderately to severely active ulcerative colitis who have had an inadequate response to conventional therapy.

Etanercept $\dagger$

Rheumatoid arthritis:

- Etanercept is indicated for reducing signs and symptoms, inducing major clinical response, inhibiting the progression of structural damage, and improving physical function in patients with moderately to severely active rheumatoid arthritis. Etanercept can be initiated in combination with methotrexate or used alone.

Polyarticular-course juvenile rheumatoid arthritis:

- Etanercept is indicated for reducing signs and symptoms of moderately to severely active polyarticular-course juvenile rheumatoid arthritis in patients who have had an inadequate response to one or more DMARDs.

Psoriatic arthritis:

- Etanercept is indicated for reducing signs and symptoms, inhibiting the progression of structural damage of active arthritis, and improving physical function in patients with psoriatic arthritis.

- Etanercept can be used in combination with methotrexate in patients who do not respond adequately to methotrexate alone.

Ankylosing spondylitis:

- Etanercept is indicated for reducing signs and symptoms in patients with active ankylosing spondylitis.

Plaque psoriasis:

- Etanercept is indicated for the treatment of adult patients (18 years or older) with chronic moderate-to-severe plaque psoriasis who are candidates for systemic therapy or phototherapy.

Adalimumab $\ddagger$

\section{Rheumatoid arthritis:}

- Adalimumab is indicated for reducing signs and symptoms, including major clinical response, inhibiting the progression of structural damage and improving physical function in adult patients with moderately to severely active rheumatoid arthritis. Adalimumab can be used alone or in combination with methotrexate or other DMARDs.

Psoriatic arthritis:

- Adalimumab is indicated for reducing signs and symptoms of active arthritis in patients with psoriatic arthritis. Adalimumab can be used alone or in combination with DMARDs.

Ankylosing spondylitis:

- Adalimumab is indicated for reducing signs and symptoms in patients with active ankylosing spondylitis.

* Centocor. Remicade [prescribing information]. Revised May 2006. Available at: http://www.remicade.com/pdf/HCP_PPI.pdf. Accessed August 10, 2006.

† Amgen and Wyeth. Enbrel [prescribing information]. Issue date: April 27, 2006. Available at: http://www.enbrel.com/prescribing-information.jsp. Accessed August 10, 2006

₹ Abbott Laboratories. Humira (adalimumab) [prescribing information]. Ref: 03-5516-R9. Revised July 2006. Available at: http://www.rxabbott.com/ pdf/humira.pdf. Accessed August 10, 2006

DMARDs = disease-modifying antirheumatic drugs; FDA=U.S. Food and Drug Administration; TNF- $\alpha=$ tumor necrosis factor-alpha.

traditional DMARDs, ${ }^{5-8}$ but they are associated with greater costs (including costs of drugs and of health resource utilization). These costs, when accumulated over the duration of the condition, are of interest to potential payers.

In recent years, a number of evaluations have assessed the economic value of biologics for the management of RA. Several review papers have been published based on this body of literature, which either focused on comparing the underlying methodologies across studies or provided a review of a single biologic.-12 In contrast, the present review aims to provide decision makers with the results of research performed to determine the potential economic value of biologic DMARDs (i.e., TNF- $\alpha$ inhibitors) and to highlight special considerations when interpreting results for formulary decisions. Specifically, the objective of this article is to provide a comprehensive review of the literature on cost-effectiveness analyses (CEAs) and cost- 
Review of Eight Pharmacoeconomic Studies of the Value of Biologic DMARDs (Adalimumab, Etanercept, and Infliximab) in the Management of Rheumatoid Arthritis

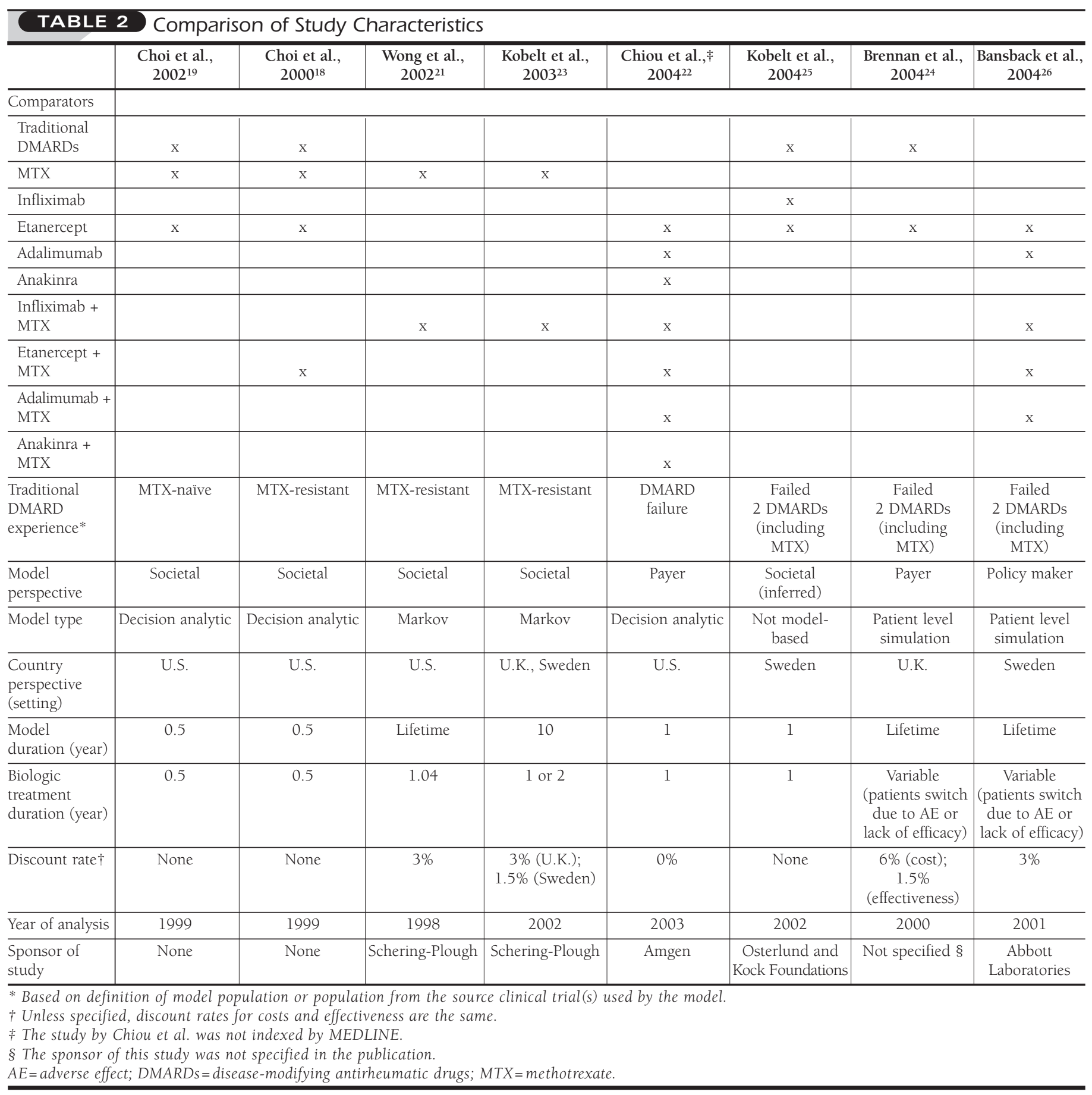

utility analyses (CUAs) of biologic DMARD treatments for RA, specifically for the 3 TNF- $\alpha$ inhibitors (adalimumab, etanercept, and infliximab).

The TNF- $\alpha$ inhibitors adalimumab, etanercept, and infliximab (the latter only in combination with methotrexate) are recommended as options for the treatment of adults who have both of the following characteristics: (1) continuing clinically active and severe RA as measured by disease activity score $($ DAS28) $>5.1$ (i.e., highly active disease)_disease activity should be measured at 2 time points, 1 month apart, confirming ongoing active disease; and (2) have received at least 2 adequate trials of DMARDs, including methotrexate (unless contraindicated). 


\section{Review of Eight Pharmacoeconomic Studies of the Value of Biologic DMARDs (Adalimumab, Etanercept, and Infliximab) in the Management of Rheumatoid Arthritis}

An adequate trial of a DMARD is defined as (1) treatment for at least 6 months, with at least 2 months at a standard target dose unless significant toxicity limited the dose tolerated; or (2) treatment for $<6$ months where treatment was withdrawn because of drug intolerance or toxicity, but normally after at least 2 months at therapeutic doses. ${ }^{13}$

\section{Methods}

A comprehensive literature search of the MEDLINE and HealthSTAR databases was conducted using cost-benefit analysis, rheumatoid arthritis, antirheumatic agents, and antineoplastic and immunosuppressive agents as search terms and/or MeSH (medical subject headings) titles (from 1966 through November 2004). Published articles that conducted a formal cost-efficacy, cost-effectiveness, or cost-utility analysis of adalimumab, etanercept, or infliximab in RA were included. Studies were excluded if they were not in the relevant population, did not include the interventions of interest, were not in the English language, did not involve human subjects, or were review articles. After a review of the titles and abstracts, 7 full-text papers were obtained for all relevant studies. One additional study published in a pharmacoeconomics journal that was not indexed in MEDLINE or HealthSTAR was included based on the recommendation of one of the authors (Chiou). Data were collected on the comparators studied, patient characteristics, data sources, model assumptions, costs, effectiveness, and incremental cost-effectiveness ratios (ICERs).

These studies reported costs from different years and in different currencies. To reduce the variation, costs were reported in 2 ways: (1) expressed as the value documented in the year when the analysis was conducted and (2) converted to 2004 U.S. dollars (USD) using the medical care component of the Consumer Price Index (CPI) for studies done in prior years. ${ }^{14}$ For studies that expressed costs in currencies other than USD, a currency exchange rate was applied to convert their values into USD, and then the CPI was applied to adjust costs to their 2004 values. In this article, costs represent the values in the base year during which the authors conducted their models and/or analyses. Where indicated, adjusted costs represent values in 2004 USD.

Because the value of a reported ICER depends on which reference comparator was chosen, large differences could be observed across studies that employed different methods of calculation. For this review, 2 methods were used to standardize the reporting of the ICERs. In the first method, comparators were rank ordered from the least to the most costly. Alternatives that were both more costly and less effective than another option (i.e., dominated) were eliminated from consideration. ICERs were calculated and reported among the remaining alternatives. Alternatively, the ICERs were calculated using a common reference comparator; in most instances, the comparator was methotrexate.
The quality of each study was assessed using the Quality of Health Economic Studies (QHES) instrument. ${ }^{15,16}$ This instrument has 16 criteria that cover areas of methodology, valid and transparent results, and comprehensive reporting of the results. ${ }^{15}$ Each criterion has a weighted point value: a maximum total score of 100 is possible, and a higher score implies better quality. A study with a score $>75$ can be considered of "good" quality. Furthermore, having a score that represents the quality of a study could be useful to identify studies that should receive more attention and be given greater weight in the decisionmaking process. Greater familiarity and application of the QHES instrument could facilitate systematic evaluation of costeffectiveness literature.

\section{Results}

From a total of 180 titles identified, 155 were excluded for the following reasons: 89 because they did not consider the drugs of interest, 15 because the population was not RA, 19 because they had the wrong drugs and population, 22 because they were review articles, and 10 because they were general articles. Twenty-five abstracts were accepted for further review. Of these, 13 were subsequently selected for full-text review. Three of the 13 were excluded because the drugs of interest were not included. Another 3 of the 13 were excluded because they were review articles. One of the authors identified a study not indexed in MEDLINE. Ultimately, 2 cost-effectiveness and 6 cost-utility studies were selected for this critical review. Two were CEAs, which defined effectiveness based on ACR criteria. ACR 20 was defined as $\geq 20 \%$ improvement in tender and swollen joint counts and $\geq 20 \%$ improvement in 3 of 5 other core measures: patient's global assessment, physician's global assessment, physical disability score, acute-phase reactant value, and patient's assessment of pain. ${ }^{17}$ The remaining studies were CUAs, which defined effectiveness as quality-adjusted life-years (QALYs). Table 2 shows distinct variation across studies in terms of comparators evaluated, perspectives, model duration, treatment duration, and discount rate.

Using the QHES instrument, all studies achieved scores of $\geq 78$, and scores ranged from 78 to 92 (Table 3). Studies with lower scores tended to evaluate RA over a time period of $<1$ year, did not discuss direction and magnitude of potential biases, and/or did not adequately present study limitations.

\section{Cost-Effectiveness Studies: Cost per Patient Achieving ACR Response}

Choi et al. conducted 2 CEAs ${ }^{18,19}$; one study involved a population naive to methotrexate treatment, and the other involved a population resistant to methotrexate. The ACR and BSR guidelines recommend the use of biologics after failure to respond to traditional DMARDs. Therefore, the results of the study among methotrexate-naive patients should not be given much weight, although we have summarized them here for completeness. 
Review of Eight Pharmacoeconomic Studies of the Value of Biologic DMARDs (Adalimumab, Etanercept, and Infliximab) in the Management of Rheumatoid Arthritis

\begin{tabular}{|c|c|c|c|c|c|c|c|c|}
\hline Criterion* & Choi, 2002 & Choi, 2000 & Wong, 2002 & Kobelt, 2003 & Chiou, 2004 & Kobelt, 2004 & Brennan, 2004 & Bansback, 2004 \\
\hline 1 & + & + & + & + & + & + & + & + \\
\hline 2 & + & + & + & + & + & - & + & + \\
\hline 3 & + & + & + & + & + & + & + & + \\
\hline 4 & - & - & - & - & - & - & - & - \\
\hline 5 & + & + & + & + & + & + & + & + \\
\hline 6 & + & + & + & + & + & + & + & + \\
\hline 7 & + & + & + & + & - & + & + & + \\
\hline 8 & - & - & + & + & - & - & + & + \\
\hline 9 & + & + & + & + & + & + & + & + \\
\hline 10 & - & - & + & + & + & + & + & + \\
\hline 11 & - & - & + & + & + & + & - & - \\
\hline 12 & + & + & - & + & + & + & + & + \\
\hline 13 & + & + & - & - & + & + & + & + \\
\hline 14 & + & + & - & + & - & + & + & - \\
\hline 15 & + & + & + & + & + & + & + & + \\
\hline 16 & + & + & + & + & - & + & - & + \\
\hline Total & 79 & 79 & 78 & 92 & 78 & 88 & 89 & 86 \\
\hline
\end{tabular}

+ Study met the criterion.

- All or part of the criterion was not met.

* Sixteen criteria of the Quality of Health Economic Studies (QHES) instrument ${ }^{15,16}$ :

$1 \quad$ Was the study objective presented in a clear, specific, and measurable manner? (7 points)

2 Were the perspective of the analysis (societal, third-party payer, etc.) and reasons for its selection stated? (4 points)

3 Were variable estimates used in the analysis from the best available source (i.e., Randomized Control Trial—Best, Expert Opinion-Worst)? (8 points)

4 If estimates came from a subgroup analysis, were the groups pre-specified at the beginning of the study? ( 1 point)

5 Was uncertainty handled by: 1) statistical analysis to address random events; 2) sensitivity analysis to cover a range of assumptions? (9 points)

$6 \quad$ Was incremental analysis performed between alternatives for resources and costs? (6 points)

7 Was the methodology for data abstraction (including value health states and other benefits) stated? (5 points)

8 Did the analytic horizon allow time for all relevant and important outcomes? Were benefits and costs that went beyond one year discounted (3\%-5\%) and justification given for the discount rate? (7 points)

9 Was the measurement of costs appropriate and the methodology for the estimation of quantities and unit costs clearly described? (8 points)

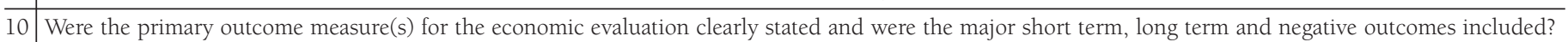
(6 points)

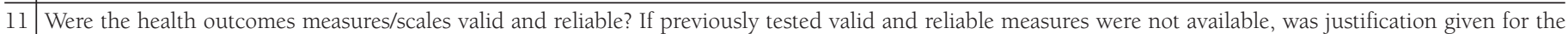
measures/scales used? (7 points)

12 Were the economic model (including structure), study methods and analysis, and the components of the numerator and denominator displayed in a clear transparent manner? (8 points)

13 Were the choice of economic model, main assumptions and limitations of the study stated and justified? (7 points)

14 Did the author(s) explicitly discuss direction and magnitude of potential biases? (6 points)

15 Were the conclusions/recommendations of the study justified and based on the study results? (8 points)

16 Was there a statement disclosing the source of funding for the study? (3 points)

Both analyses used a decision tree to model events that may occur within 6 months of initiation of various therapies (Table 4). Outcomes in the models were based on ACR response and the occurrence of toxicity related to each therapy.
Among a methotrexate-naive population, Choi et al. compared the cost-effectiveness of etanercept, leflunomide, methotrexate, and sulfasalazine compared with no second-line agent (Table 4). ${ }^{18}$ When the effectiveness measure was defined 
Review of Eight Pharmacoeconomic Studies of the Value of Biologic DMARDs (Adalimumab, Etanercept, and Infliximab) in the Management of Rheumatoid Arthritis

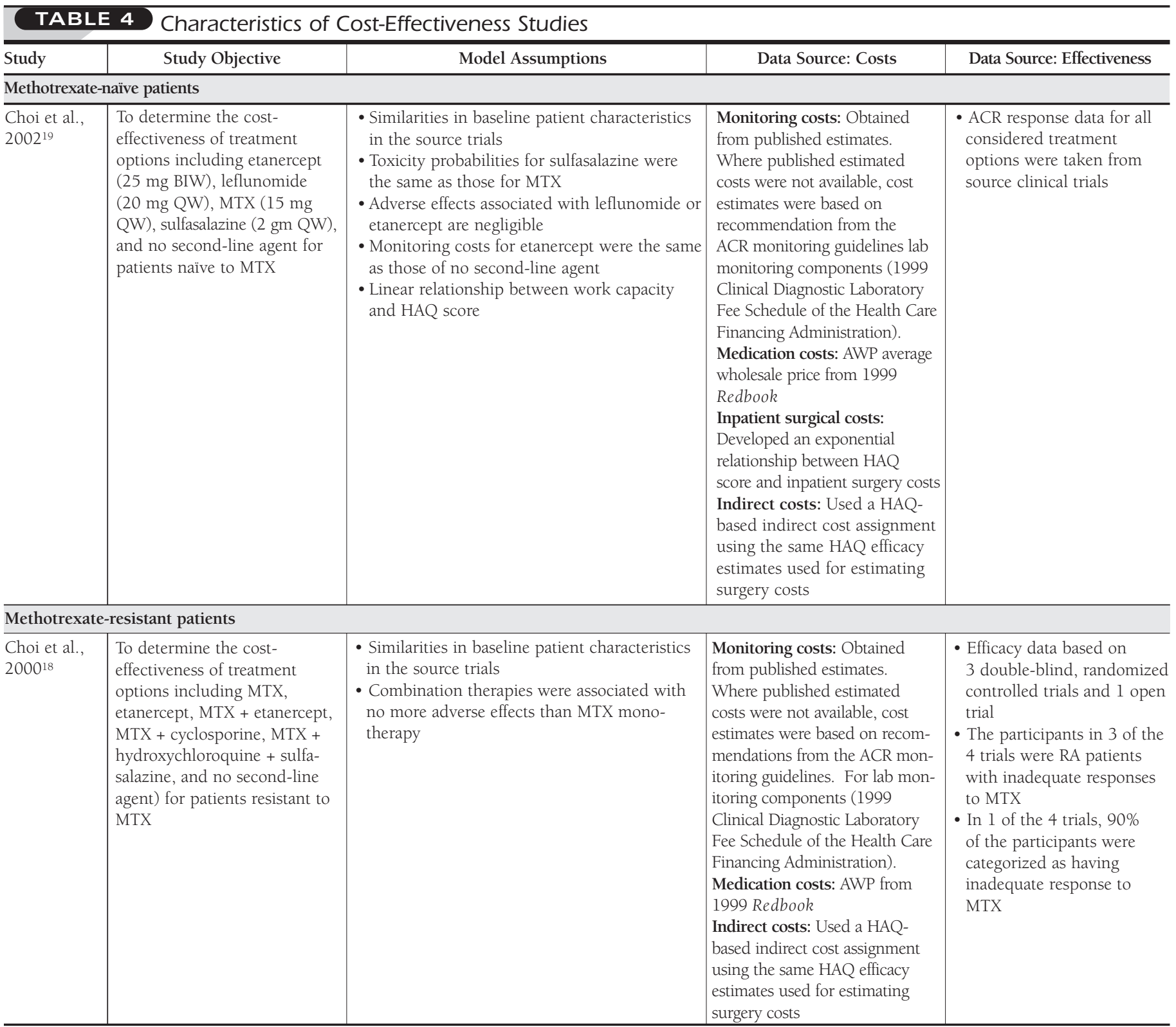

$A C R=$ American College of Rheumatology; $A W P=$ average wholesale price; $B I W=$ twice per week; HAQ = Health Assessment Questionnaire; $M T X=$ methotrexate $; W=$ daily; $R A=$ rheumatoid arthritis.

as either the ACR20 or the ACR70 weighted response, methotrexate was the lowest-cost option and etanercept was the highestcost option. The least effective option was no second-line agent at 0.27 , and the most effective option was etanercept at 0.68 . Compared with methotrexate, etanercept was associated with an ICER of $\$ 40,300$ per patient with an ACR20 response $(\$ 49,900$, 2004 USD) over a 6-month period (Table 5). This is interpreted as the additional cost per patient to achieve an ACR20 response. In 1-way sensitivity analyses, the ICER per patient achieving
ACR20 improvement for etanercept was greater than $\$ 39,000$ unless the cost of etanercept was reduced or the probability of achieving ACR20 response was increased. When the baseline cost of etanercept $(\$ 6,600)$ was reduced by $25 \%$ and $50 \%$, the ICERs compared with methotrexate were $\$ 28,400$ and $\$ 15,000$, respectively, per ACR20. When the probability of achieving ACR20 (81\%) was increased by $20 \%$, the ICER was $\$ 17,700$ compared with methotrexate.

Among methotrexate-resistant patients, Choi et al. analyzed 
Review of Eight Pharmacoeconomic Studies of the Value of Biologic DMARDs (Adalimumab, Etanercept, and Infliximab) in the Management of Rheumatoid Arthritis

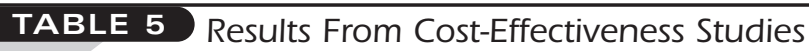

\begin{tabular}{|c|c|c|c|c|c|}
\hline Study & Comparator & Total Costs* & ACR Response & $\begin{array}{c}\text { Costs per Additional } \\
\text { Patient Achieving ACR20* } \dagger\end{array}$ & $\begin{array}{c}\text { Costs per Additional } \\
\text { Patient Achieving ACR20*政 }\end{array}$ \\
\hline \multicolumn{6}{|c|}{ Methotrexate-naïve patients } \\
\hline \multirow[t]{5}{*}{ Choi et al., $2002^{19}$} & MTX & $\$ 10,926(\$ 13,541)$ & 0.55 & Reference & N/A \\
\hline & Sulfasalazine & $\$ 11,027(\$ 13,666)$ & 0.56 & $\$ 10,100(\$ 12,500)$ & $\$ 10,100(\$ 12,500)$ \\
\hline & No second-line agent & $\$ 11,379(\$ 14,102)$ & 0.27 & Dominated & Dominated \\
\hline & Leflunomide & $\$ 11,428(\$ 14,163)$ & 0.55 & Dominated & Dominated \\
\hline & Etanercept & $\$ 16,165(\$ 20,034)$ & 0.68 & $\$ 40,300(\$ 49,900)$ & $\$ 42,800(\$ 53,000)$ \\
\hline \multicolumn{6}{|c|}{ Methotrexate-resistant patients } \\
\hline \multirow[t]{6}{*}{ Choi et al., $2000^{18}$} & No second-line agent & $\$ 12,842(\$ 15,915)$ & 0.11 & Reference & N/A \\
\hline & $\begin{array}{c}\text { MTX + hydroxychloroquine } \\
+ \text { sulfasalazine }\end{array}$ & $\$ 13,492(\$ 16,721)$ & 0.55 & $\$ 1,500(\$ 1,800)$ & $\$ 1,500(\$ 1,800)$ \\
\hline & MTX & $\$ 13,810(\$ 17,115)$ & 0.27 & $\$ 6,500(\$ 7,500)$ & Dominated \\
\hline & MTX + cyclosporine & $\$ 14,780(\$ 18,317)$ & 0.55 & $\$ 4,400(\$ 5,500)$ & Dominated \\
\hline & Etanercept monotherapy & $\$ 18,180(\$ 22,531)$ & 0.61 & $\$ 10,700(\$ 13,200)$ & $\$ 78,100(\$ 96,800)$ \\
\hline & MTX + etanercept & $\$ 19,083(\$ 23,650)$ & 0.68 & $\$ 10,900(\$ 13,600)$ & $\$ 12,900(\$ 16,000)$ \\
\hline
\end{tabular}

* Costs are reported in the year of analysis; (costs are adjusted to 2004 U.S. dollars as shown in parentheses).

+ ICERs are calculated by comparing each comparator to the reference. Choi et al. rounded costs to the nearest hundred.

\# ICERs are calculated by comparing each comparator to the next best nondominated agent. Choi et al. rounded costs to the nearest hundred.

ACR20 = American College of Rheumatology 20\% response criteria; ICER=incremental cost-effectiveness ratio; $M T X=m e t h o t r e x a t e ;$

N/A = not applicable

the cost-effectiveness of 6 treatments: methotrexate monotherapy, etanercept monotherapy, methotrexate plus etanercept, methotrexate plus cyclosporine, methotrexate plus hydroxychloroquine plus sulfasalazine, and no second-line agent. ${ }^{19}$ Efficacy data were based on 3 double-blind randomized controlled trials (RCTs) and 1 open-label trial. ACR response data were collected from the source clinical trials and used to estimate the probabilities of achieving an ACR response for each of the comparators. The authors assumed that patient characteristics in the source trials were similar based on similar RA duration and Health Assessment Questionnaire (HAQ) disability score. HAQ assesses arthritis-related functional disability in activities such as dressing, arising, eating, walking, hygiene, and reaching and gripping. ${ }^{20}$ The HAQ score ranges from 0 to 3; a higher score indicates greater disability. Also, combination therapies were assumed to be associated with no more adverse effects than methotrexate monotherapy, which was suggested by findings from individual trials. Defining ACR20 as the effectiveness measure resulted in the "no secondline agent" option being the lowest cost and least cost-effective option, and methotrexate plus etanercept being the highest-cost and most cost-effective option, over the 6-month model duration (Table 5). When compared with methotrexate, the triple therapy option (methotrexate-hydroxychloroquinesulfasalazine) resulted in an ICER of $\$ 1,500$ per patient with ACR20 response over a 6-month period. The ACR guidelines support the use of triple therapy prior to biologics, and this study supported the cost-effectiveness of this strategy. Etanercept monotherapy was calculated to have an ICER of $\$ 10,700$ per patient with ACR20 response $(\$ 13,220,2004$ USD) when compared with methotrexate. The ICER for the methotrexate-plus-etanercept option was calculated to be $\$ 10,900$ per patient with ACR20 response (\$13,600, 2004 USD).

\section{Cost-Utility Studies: Cost per QALY Gained}

Six studies used QALYs as the effectiveness measure. Of these, 2 were conducted in the United States and 4 were in other countries. These economic models were based on studies that evaluated RA patients who failed at least 1 DMARD and/or who were methotrexate-resistant. Because of inadequate response to previous trial(s) of DMARDs, patients entering these models were considered eligible for biologics.

\section{U.S. Studies}

Wong et al. (Table 6) compared methotrexate alone with infliximab plus methotrexate in patients with active, refractory RA. ${ }^{21}$ A Markov model was constructed based on pairwise combinations of treatments and disability levels, as measured by the HAQ and death. Two key assumptions were that mortality increased by 1.77-fold for each increase in disability level and that infliximab would be discontinued after 54 weeks of therapy; those patients would then receive methotrexate, but clinical benefit would 
Review of Eight Pharmacoeconomic Studies of the Value of Biologic DMARDs (Adalimumab, Etanercept, and Infliximab) in the Management of Rheumatoid Arthritis

\section{TABLE 6 Characteristics of Cost-Utility Studies}

\begin{tabular}{|c|c|c|c|c|}
\hline Study & Study Objective & Model Specifications and Assumptions & Data Source: Costs & Data Source: Effectiveness \\
\hline $\begin{array}{l}\text { Wong } \\
\text { et al., } \\
2002^{21}\end{array}$ & $\begin{array}{l}\text { To estimate the cost- } \\
\text { effectiveness of infliximab } \\
+ \text { methotrexate }(\geq 12.5 \\
\text { mg/week) compared } \\
\text { with methotrexate } \\
\text { ( } \geq 12.5 \mathrm{mg} \text { /week) alone } \\
\text { for patients with active } \\
\text { and refractory RA }\end{array}$ & $\begin{array}{l}\text { - Markov model with } 21 \text { states of health based on pair- } \\
\text { wise combination of } 5 \text { treatments (MTX + infliximab, } \\
\text { MTX, DMARD, MTX + DMARD, and corticosteroid or } \\
\text { NSAID) } \\
\text { - Four disability levels as measured by the HAQ (no, } \\
\text { mild, or advanced impairment; and death) } \\
\text { - Treatment according to ATTRACT protocol during lst } \\
\text { year. After, the disability score and current treatment } \\
\text { affected the likelihood of whether the disability level } \\
\text { improved, worsened, or stayed the same over 6-month } \\
\text { periods. } \\
\text { - HRQoL was assessed as self-reported global health using } \\
\text { a visual analog scale (0 to 100), rescaled so that 0 = death } \\
\text { and } 1.0 \text { = perfect health (Year } 1 \text { from ATTRACT, >Year } 1 \\
\text { from ARAMIS). } \\
\text { - Mortality compared with an age-and sex-matched } \\
\text { general population was } 1.77 \text {-fold greater for each } \\
\text { increase in disability level. } \\
\text { - Infliximab would be discontinued after } 54 \text { weeks of } \\
\text { therapy and that patients would then receive MTX. } \\
\text { - Clinical benefits diminished over time, not immediately } \\
\text { at discontinuation of infliximab. } \\
\text { did not consider dose reductions for side effects or }\end{array}$ & $\begin{array}{l}\text { Drug costs: Based on AWP, } \\
\text { infusion administration } \\
\text { costs, and pretreatment } \\
\text { evaluation } \\
\text { Direct costs: Taken from } \\
\text { ATTRACT and included all } \\
\text { non-protocol-related med- } \\
\text { ical care costs } \\
\text { Indirect costs: First year, } \\
\text { taken from ATTRACT for } \\
\text { the subset of patients who } \\
\text { were employed at time of } \\
\text { enrollment; remaining } \\
\text { years, estimated as } 1 \text { or } 3 \\
\text { times the direct costs }\end{array}$ & $\begin{array}{l}\text { Year 1: Data from ATTRACT } \\
\text { Remaining years: Data from } \\
\text { ARAMIS. ARAMIS is a Post- } \\
\text { Marketing Surveillance Program, } \\
\text { which has prospectively enrolled } \\
4,258 \text { patients with RA who } \\
\text { were followed for } 17,085 \\
\text { patient-years at } 8 \text { representative } \\
\text { North American clinical practices. }\end{array}$ \\
\hline $\begin{array}{l}\text { Chiou } \\
\text { et al., } \\
2004^{22}\end{array}$ & $\begin{array}{l}\text { To estimate the direct } \\
\text { costs and cost-effective- } \\
\text { ness of biologic treat- } \\
\text { ments for RA: (1) adali- } \\
\text { mumab ( } 40 \mathrm{mg} \text { QOW), } \\
\text { (2) anakinra (100 mg } \\
\text { QW), (3) etanercept } \\
(25 \mathrm{mg} \text { BIW), } \\
\text { (4) methotrexate ( } 15 \mathrm{mg} \\
\text { QW) + adalimumab } \\
\text { ( } 40 \text { mg QOW), } \\
\text { (5) methotrexate ( } 15 \mathrm{mg} \\
\text { QW) + anakinra ( } 100 \mathrm{mg} \\
\text { QD), (6) methotrexate } \\
\text { ( } 15 \mathrm{mg} \text { QW) + } \\
\text { etanercept ( } 25 \text { mg } \\
\text { BIW), ( } 7) \text { methotrexate } \\
\text { ( } 15 \text { mg QW) + } \\
\text { infliximab ( } 3 \text { mg/kg QW } \\
\text { with a loading dose of } \\
8 \text { doses/year) }\end{array}$ & $\begin{array}{l}\text { - Did not include non-treatment-related adverse events, } \\
\text { potential improvement in long-term clinical outcomes, } \\
\text { or indirect costs. } \\
\text { - Effectiveness is measured at } 6 \text { months and } 12 \text { months. } \\
\text { - Where } 12 \text {-month effectiveness rates were not available, } \\
6 \text {-month and } 12 \text {-month effectiveness rates were assumed } \\
\text { to be equivalent. }\end{array}$ & $\begin{array}{l}\text { Drug costs: U.S. AWP } \\
2003 \text { Healthcare Resource } \\
\text { Costs: Obtained from the } \\
2003 \text { American Medical } \\
\text { Association Current } \\
\text { Procedural Terminology } \\
\text { codebook, the } 2003 \\
\text { Medicare Reimbursement } \\
\text { Fee Schedule, and the } \\
\text { Medstat Diagnosis-Related } \\
\text { Group guide }\end{array}$ & $\begin{array}{l}\text { Efficacy data based on } \\
10 \text { double-blind randomized } \\
\text { controlled trials with } \\
\text { comparable patient } \\
\text { characteristics as selected } \\
\text { by a panel of experts }\end{array}$ \\
\hline $\begin{array}{l}\text { Brennan } \\
\text { et al., } \\
2004^{24}\end{array}$ & $\begin{array}{l}\text { To assess the cost- } \\
\text { effectiveness of } \\
\text { etanercept monotherapy } \\
\text { compared with current } \\
\text { care consisting of a } \\
\text { series of traditional } \\
\text { DMARDs (IM gold, } \\
\text { leflunomide, } \\
\text { methotrexate plus } \\
\text { cyclosporine) in } \\
\text { accordance with } \\
\text { BSR guidelines }\end{array}$ & $\begin{array}{l}\text { - Patients had failed at least } 2 \text { DMARDs that included } \\
\text { MTX and sulfasalazine. Patients on etanercept mono- } \\
\text { therapy can receive the traditional DMARD series if } \\
\text { occurrence of adverse effects or lack of efficacy. } \\
\text { - Steroids are not modeled because they are low in cost } \\
\text { and because normal use is alongside DMARDs rather } \\
\text { than as alternatives. } \\
\text { - Base-case analysis does not include home help, residential } \\
\text { nursing home care costs, and worker productivity. } \\
\text { - Clinical benefits diminished immediately upon dis- } \\
\text { continuation of etanercept. } \\
\text { - Cycle length of } 6 \text { months }\end{array}$ & $\begin{array}{l}\text { Drug costs: Derived from } \\
\text { current list prices reported } \\
\text { in the Monthly Index of } \\
\text { Medical Specialities } \\
\text { (MIMS) [United Kingdom] } \\
\text { Drug monitoring: } \\
\text { Estimated by costing BSR } \\
\text { guidelines } \\
\text { Direct costs: Included } \\
\text { general practitioner, } \\
\text { outpatient, and hospital } \\
\text { Other direct costs: } \\
\text { Included costs for general } \\
\text { practitioner, outpatient } \\
\text { services, and hospitalization. } \\
\text { Differences in HAQ scores } \\
\text { between comparators were } \\
\text { used to model differences } \\
\text { in direct costs. }\end{array}$ & $\begin{array}{l}\text { - Baseline characteristics for the } \\
\text { population examined are based } \\
\text { on the published etanercept } \\
\text { monotherapy trial. } \\
\text { - Treatments are based on } \\
\text { both the U.K. ERAS, and a } \\
\text { commercially available } \\
\text { electronic general practice } \\
\text { database (DINLINK, } \\
\text { Compufile). } \\
\text { (continued on next page) }\end{array}$ \\
\hline
\end{tabular}


Review of Eight Pharmacoeconomic Studies of the Value of Biologic DMARDs (Adalimumab, Etanercept, and Infliximab) in the Management of Rheumatoid Arthritis

\section{TABLE 6 Characteristics of Cost-Utility Studies (continued)}

\begin{tabular}{|c|c|c|c|c|}
\hline Study & Study Objective & Model Specifications and Assumptions & Data Source: Costs & Data Source: Effectiveness \\
\hline $\begin{array}{l}\text { Kobelt } \\
\text { et al., } \\
2003^{23}\end{array}$ & $\begin{array}{l}\text { To estimate the cost- } \\
\text { utility of infliximab } \\
\text { (initial treatment at } \\
\text { weeks } 0,2 \text {, and } 6 \text {, then } \\
\text { given at either } 3 \mathrm{mg} / \mathrm{kg} \\
\text { or } 10 \mathrm{mg} / \mathrm{kg} \text { dose every } \\
4 \text { or } 8 \text { weeks) plus } \\
\text { methotrexate ( } \geq 12.5 \mathrm{mg} \\
\text { QW) compared with } \\
\text { methotrexate alone } \\
\text { ( } \geq 12.5 \text { mg QW) in } \\
\text { inadequately controlled } \\
\text { RA }\end{array}$ & $\begin{array}{l}\text { - Treatment was stopped after } 1 \text { or } 2 \text { years, when no } \\
\text { further clinical data were available, and no further } \\
\text { treatment costs and effects were therefore assumed. } \\
\text { - NSAID usage was not included, as most patients used } \\
\text { them and usage did not differ significantly between } \\
\text { states. } \\
\text { - Clinical benefits diminished over time and not immediately } \\
\text { at discontinuation of infliximab. }\end{array}$ & $\begin{array}{l}\text { Cost of hospitalization: } \\
\text { Based on the number of } \\
\text { inpatient days in different } \\
\text { wards and ward-specific } \\
\text { daily costs } \\
\text { Surgical intervention: } \\
\text { Calculated from the type } \\
\text { of intervention and its } \\
\text { duration multiplied by } \\
\text { the cost per minute of } \\
\text { operating theatre use } \\
\text { Outpatient care: Based } \\
\text { on the number of visits } \\
\text { to different health care } \\
\text { professionals } \\
\text { Drug cost: Calculated from } \\
\text { the number of months of } \\
\text { use of each drug, associated } \\
\text { with the cost of standard } \\
\text { drug monitoring protocols } \\
\text { in place in the rheumatol- } \\
\text { ogy departments partici- } \\
\text { pating. Unit costs were } \\
\text { taken from hospital } \\
\text { accounting data and official } \\
\text { price lists from National } \\
\text { Health Service (U.K.) and } \\
\text { University Hospital Lund } \\
\text { (Sweden). } \\
\text { Indirect costs: Calculated } \\
\text { using the human capital } \\
\text { approach, in which an } \\
\text { individual's productivity is } \\
\text { valued at the market price }\end{array}$ & $\begin{array}{l}\text { Year 1: Data from the ATTRACT } \\
\text { trial } \\
\text { Beyond year 1: Disease } \\
\text { progression was modeled based } \\
\text { on changes in HAQ scores from } \\
\text { epidemiological cohorts called } \\
\text { Lund Cohort Study (Sweden) } \\
\text { and ERAS (U.K.). }\end{array}$ \\
\hline $\begin{array}{l}\text { Kobelt } \\
\text { et al., } \\
200425\end{array}$ & $\begin{array}{l}\text { To evaluate costs, } \\
\text { benefits, and cost- } \\
\text { effectiveness of } \\
\text { etanercept or infliximab } \\
\text { treatment over 1-year } \\
\text { period compared with } \\
\text { no biologic }\end{array}$ & $\begin{array}{l}\text { - Comparator represented a group with costs and benefits } \\
\text { that were established from baseline and were assumed to } \\
\text { remain the same throughout the year. That is, comparison } \\
\text { with another RA agent was not conducted. } \\
\text { - Improvement in utility occurred after } 3 \text { months of treat- } \\
\text { ment (base case). }\end{array}$ & \begin{tabular}{|l|} 
Structured interview: \\
Obtained resource \\
consumption and work \\
capacity data for the year \\
before treatment and the \\
first anti-TNF year \\
Indirect costs: Estimated \\
by human capital method \\
using average annual gross \\
salary; sick days and loss of \\
productivity were included
\end{tabular} & $\begin{array}{l}\text { Data collected from } 116 \text { patients } \\
\text { recruited from } 4 \text { rheumatology } \\
\text { centers in Sweden }\end{array}$ \\
\hline $\begin{array}{l}\text { Bansback } \\
\text { et al., } \\
200426\end{array}$ & $\begin{array}{l}\text { To conduct a cost- } \\
\text { effectiveness analysis of } \\
\text { adalimumab relative to } \\
\text { different biologic and } \\
\text { nonbiologic DMARDs } \\
\text { in the treatment of } \\
\text { moderate-to-severe RA }\end{array}$ & $\begin{array}{l}\text { - Indirect comparisons were made between biologics } \\
\text { because of lack of head-to-head trials. } \\
\text { - Investigators assumed that moderate DAS28 response } \\
\text { and good DAS28 response correlated well to ACR20 and } \\
\text { ACR50, respectively. } \\
\text { - Where there are limited data on ACR response rates for } \\
\text { DMARDs, they were assumed to be equal to lefluno- } \\
\text { mide. } \\
\text { - Clinical benefits diminished immediately upon discon- } \\
\text { tinuation of biologic DMARDs. } \\
\text { - Two sets of analyses were conducted based on ACR20 } \\
\text { and ACR50 responses. }\end{array}$ & $\begin{array}{l}\text { Sources of cost data were } \\
\text { not specified; health care } \\
\text { resource utilizations were } \\
\text { modeled as a function of } \\
\text { HAQ-DI }\end{array}$ & $\begin{array}{l}\text { Response rate: Data came } \\
\text { from published articles and } \\
\text { conference abstracts. } \\
\text { Adverse events: Obtained from } \\
\text { observational study } \\
\text { HRQoL: HUI-3 was used to } \\
\text { measure health utility in all } \\
\text { adalimumab trials. Analysis of } \\
\text { 2,000 patients from trial data } \\
\text { allowed for linear transformation } \\
\text { of disability (HAQ) to HRQoL } \\
\text { (HUI-3). }\end{array}$ \\
\hline
\end{tabular}

ACR20 = American College of Rheumatology 20\% response criteria; ACR50=American College of Rheumatology $50 \%$ response criteria; ARAMIS = Arthritis,

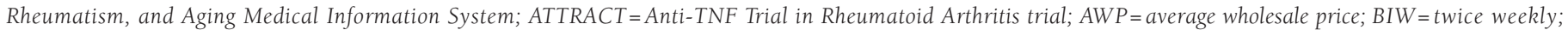
$B S R=$ British Society of Rheumatology; DAS28=Disease Activity Score (including a 28-joint count); DMARDs=disease-modifying antirheumatic drugs; ERAS= Early Rheumatoid Arthritis Study; HAQ=Health Assessment Questionnaire; HAQ-DI=Health Assessment Questionnaire Disability Index; HRQoL=health-related quality of life; HUI-3= Health Utility Index-3; IM=intramuscular; MTX=methotrexate; NSAID=nonsteroidal anti-inflammatory drug; QD=daily; QOW=every other week; QW=every week; RA=rheumatoid arthritis; TNF=tumor necrosis factor. 
decline over time. In the base case, the combination therapy exhibited both higher costs and higher efficacy, which resulted in a calculated ICER of $\$ 9,100$ per QALY gained $(\$ 11,670$, 2004 USD). After varying the age, discount rate, disability-related mortality, and long-term RA costs, the ICERs still did not exceed a commonly accepted range of $\$ 50,000$ per QALY gained.

In the study that was not indexed in MEDLINE, Chiou et al (Table 6) modeled the cost utilities of various biologic DMARD monotherapies (adalimumab, anakinra, and etanercept) and combination therapies (methotrexate plus adalimumab methotrexate plus anakinra, methotrexate plus etanercept, and methotrexate plus infliximab) among patients with moderateto-severe RA. ${ }^{22}$ Etanercept was deemed cost effective based on an ICER of $\$ 13,387$ per QALY gained as monotherapy $(\$ 13,985,2004$ USD) and an ICER of $\$ 7,925$ per QALY gained when used in combination with methotrexate $(\$ 8,279,2004$ USD) (Table 7). This study showed that, with the exception of anakinra, treatment with etanercept plus methotrexate had similar cost $(\$ 18,954)$ and efficacy (0.6919 QALYs) as adalimumab plus methotrexate ( $\$ 18,957$ and 0.6608 QALYs). However, when compared with infliximab plus methotrexate $(\$ 20,071$ and 0.5949 QALYs), etanercept plus methotrexate or adalimumab plus methotrexate were both less costly and more effective. Sensitivity analyses revealed that the cost of biologics and probabilities for achieving ACR response were the main drivers of incremental cost-effectiveness ratios. Because the costeffectiveness of biologics relative to nonbiologic agents was not compared, the findings from this study cannot be directly compared with those of other studies.

\section{Swedish and United Kingdom Studies}

Four studies examined the cost-utility of biologics from a nonU.S. perspective. Kobelt et al. presented results from both the Swedish and U.K. perspectives. ${ }^{23}$ Brennan et al. provided only a U.K. perspective. ${ }^{24}$

Kobelt et al. (2003) estimated the cost-utility of infliximab plus methotrexate compared with methotrexate alone in RA patients not adequately controlled with traditional DMARDs (Table 6). ${ }^{23}$ A Markov model was constructed with health states defined as functional disability levels (as measured by HAQ scores), and a death state. The model distributed patients into different health states based on whether their HAQ scores have improved, remained stable, or worsened, or if the patient died during the cycle. Although the duration of the model was 10 years, the treatment effects of biologics beyond 2 years were not modeled because long-term clinical data were not available. First-year efficacy data were taken from the ATTRACT (Anti-TNF Trial in Rheumatoid Arthritis with Concomitant Therapy) study, and data for years 2 through 10 were based on epidemiological observation of HAQ disability profile from the Swedish Lund Cohort study. The combination of infliximab plus methotrexate (Table 7) was both more costly and more effective compared with methotrexate alone, but the gains in QALYs were associated with a favorable cost-effectiveness profile. Results were qualitatively similar in the 1-year and 2-year analyses of biologic treatment.

In the same study, a separate analysis from the U.K. perspective was presented (Table 6). ${ }^{23}$ This model mirrored the Swedish model except that the long-term data beyond year 2 were based on a cohort from the Early RA Study ${ }^{27}$ in the United Kingdom. The combination of infliximab plus methotrexate was also found to be more expensive and more efficacious compared with methotrexate alone (Table 7). The ICER was calculated to be $£ 21,600$ (British pounds) per QALY gained $(\$ 48,710,2004$ USD).

Kobelt et al. (2004) evaluated the cost-effectiveness of etanercept or infliximab compared with routine clinical practice (i.e., without anti-TNF) for the treatment of patients with RA in Sweden (Table 6). ${ }^{25}$ Unlike other studies that were model-based analyses, this study collected actual data on direct and indirect costs, health-related quality of life (HRQoL), and HAQ scores from patients who were either resistant or intolerant of at least 2 traditional DMARDs including methotrexate. The authors concluded that the use of etanercept or infliximab in this population was cost effective because the ICER was below the generally accepted 50,000 EUR (Euros) per additional QALY gain threshold. The following yielded ICERs that did not exceed that threshold: sensitivity analyses conducted on the direct cost only, utility improvement after 6 weeks (instead of 3 months), and linear improvement in utility over 1 year. The ICERs surpassed this threshold only when an intent-to-treat analysis (including all dropouts) was conducted or when patients with low disability (HAQ score <1.6) at baseline were considered (Table 7). .

Bansback et al. conducted a lifetime CUA comparing adalimumab, etanercept, and infliximab as monotherapy and as combination therapy with methotrexate, compared with traditional DMARDs, from the perspective of a policy decision maker (Table 6) ${ }^{26} \mathrm{~A}$ hypothetical population of 10,000 patients who had failed to respond to a traditional DMARD and who were eligible for biologics entered the model. After failure with biologics, 3 other DMARDs were tried. Two versions of the model were created and analyzed based on patients achieving an ACR20 response and an ACR50 response, but these responses were translated to DAS28 response criteria. The results for adalimumab were based on the pooled results of 2 trials. HRQoL and costs were modeled as a function of the HAQ disability index. In the ACR50 version of the analysis, single and combination therapies with biologics were more costly but produced more QALYs compared with DMARDs. It is worth noting that the estimated QALY of $<3$ from this model was low considering that a lifetime analysis was conducted. In the basecase results, the ICERs were comparable across all biologics, but adalimumab plus methotrexate was the lowest at 34,922 EUR 
Review of Eight Pharmacoeconomic Studies of the Value of Biologic DMARDs (Adalimumab, Etanercept, and Infliximab) in the Management of Rheumatoid Arthritis

\section{TABLE $7 \longdiv { \text { Results From Cost-Utility Studies } }$}

\begin{tabular}{|c|c|c|c|c|c|}
\hline Study & Comparator & Total Costs* & QALYs & $\begin{array}{c}\text { Costs per } \\
\text { QALY Gained }{ }^{*}\end{array}$ & $\begin{array}{c}\text { Costs per } \\
\text { QALY Gained* }\end{array}$ \\
\hline \multicolumn{6}{|l|}{ Methotrexate-resistant patients } \\
\hline \multicolumn{6}{|l|}{ U.S. studies } \\
\hline Wong et al., $2002^{21}$ & $\begin{array}{c}\text { MTX } \\
\text { MTX + infliximab }\end{array}$ & $\begin{array}{l}\$ 313,200(\$ 401,660) \\
\$ 315,800(\$ 404,994)\end{array}$ & $\begin{array}{c}9.11 \\
9.4\end{array}$ & $\begin{array}{c}\text { Reference } \\
\$ 9,100(\$ 11,670)\end{array}$ & $\begin{array}{c}\text { N/A } \\
\$ 9,100(\$ 11,670)\end{array}$ \\
\hline Chiou et al., 200422 & $\begin{array}{c}\text { Anakinra } \\
\text { Etanercept } \\
\text { Adalimumab } \\
\text { MTX + anakinra } \\
\text { MTX + etanercept } \\
\text { MTX + adalimumab } \\
\text { MTX + infliximab }\end{array}$ & $\begin{array}{l}\$ 17,412(\$ 18,190) \\
\$ 18,333(\$ 19,152) \\
\$ 18,414(\$ 19,237) \\
\$ 18,045(\$ 18,851) \\
\$ 18,954(\$ 19,801) \\
\$ 18,957(\$ 19,804) \\
\$ 20,071(\$ 20,968)\end{array}$ & $\begin{array}{l}0.5733 \\
0.6421 \\
0.5842 \\
0.5772 \\
0.6919 \\
0.6608 \\
0.5949\end{array}$ & $\begin{array}{c}\text { Reference } \\
\$ 13,387(\$ 13,985) \\
\$ 91,927(\$ 96,034) \\
\text { Reference } \\
\$ 7,925(\$ 8,279) \\
\$ 10,909(\$ 11,397) \\
\$ 114,463(\$ 119,578)\end{array}$ & $\begin{array}{c}\text { N/A } \\
\$ 13,387(\$ 13,985) \\
\text { Dominated } \\
\text { N/A } \\
\$ 7,925(\$ 8,279) \\
\text { Dominated } \\
\text { Dominated }\end{array}$ \\
\hline \multicolumn{6}{|l|}{ U.K. studies } \\
\hline $\begin{array}{l}\text { Kobelt et al., } 2003 \\
\text { (1-year biologic treatment) }{ }^{23}\end{array}$ & $\begin{array}{c}\text { MTX } \\
\text { MTX + infliximab }\end{array}$ & $\begin{array}{l}£ 36,859(\$ 60,046) \\
£ 43,299(\$ 70,538)\end{array}$ & $\begin{array}{l}3.731 \\
4.029\end{array}$ & $\begin{array}{c}\text { Reference } \\
£ 21,600(\$ 35,188)\end{array}$ & $\begin{array}{c}\text { N/A } \\
£ 21,600(\$ 35,188)\end{array}$ \\
\hline$(2 \text {-year biologic treatment })^{23}$ & $\begin{array}{c}\text { MTX } \\
\text { MTX + infliximab }\end{array}$ & $\begin{array}{l}£ 36,859(\$ 60,046) \\
£ 48,799(\$ 79,498)\end{array}$ & $\begin{array}{l}3.731 \\
4.131\end{array}$ & $\begin{array}{c}\text { Reference } \\
£ 29,900(\$ 48,710)\end{array}$ & $\begin{array}{c}\text { N/A } \\
£ 29,900(\$ 48,710)\end{array}$ \\
\hline Brennan et al., 200424 & $\begin{array}{c}\text { DMARDs } \\
\text { Etanercept monotherapy } \\
\text { followed by DMARDs }\end{array}$ & $\begin{array}{l}£ 9,199(\$ 16,580) \\
£ 36,212(\$ 65,268)\end{array}$ & $\begin{array}{l}5.88 \\
7.53\end{array}$ & $\begin{array}{c}\text { Reference } \\
£ 16,330(\$ 29,433)\end{array}$ & $\begin{array}{c}\text { N/A } \\
£ 16,330(\$ 29,433)\end{array}$ \\
\hline \multicolumn{6}{|l|}{ Sweden studies } \\
\hline $\begin{array}{l}\text { Kobelt et al., } 2003 \\
\text { (1-year biologic treatment) }{ }^{23}\end{array}$ & $\begin{array}{c}\text { MTX } \\
\text { MTX + infliximab }\end{array}$ & $\begin{array}{l}1,121,476 \text { SEK }(\$ 125,478) \\
1,129,507 \text { SEK }(\$ 126,377)\end{array}$ & $\begin{array}{l}4.384 \\
4.632\end{array}$ & $\begin{array}{c}\text { Reference } \\
32,000 \operatorname{SEK}(\$ 3,580)\end{array}$ & $\begin{array}{c}\mathrm{N} / \mathrm{A} \\
32,000 \mathrm{SEK}(\$ 3,580)\end{array}$ \\
\hline$(2 \text {-year biologic treatment })^{23}$ & $\begin{array}{c}\text { MTX } \\
\text { MTX + infliximab }\end{array}$ & $\begin{array}{l}1,121,476 \text { SEK }(\$ 125,478) \\
1,166,298 \text { SEK }(\$ 130,493)\end{array}$ & $\begin{array}{r}4.384 \\
.683\end{array}$ & $\begin{array}{c}\text { Reference } \\
150,000 \text { SEK }(\$ 16,783)\end{array}$ & $\begin{array}{c}\text { N/A } \\
150,000 \text { SEK }(\$ 16,783)\end{array}$ \\
\hline Kobelt et al., 200425 & $\begin{array}{l}\text { Standard (nonbiologics) } \\
\text { Etanercept or infliximab }\end{array}$ & $\begin{array}{l}27,447 \text { EUR }(\$ 39,761) \\
39,630 \text { EUR }(\$ 55,972)\end{array}$ & $\begin{array}{l}0.21 \\
0.49\end{array}$ & $\begin{array}{c}\text { Reference } \\
43,500 \text { EUR }(\$ 61,438)\end{array}$ & $\begin{array}{c}\text { N/A } \\
43,500 \text { EUR }(\$ 61,438)\end{array}$ \\
\hline $\begin{array}{l}\text { Bansback et al., } 2004 \\
\text { (ACR50 analysis) }{ }^{26}\end{array}$ & $\begin{array}{c}\text { DMARD } \\
\text { Adalimumab } \\
\text { MTX + infliximab } \\
\text { Etanercept } \\
\text { MTX + adalimumab } \\
\text { MTX + etanercept }\end{array}$ & 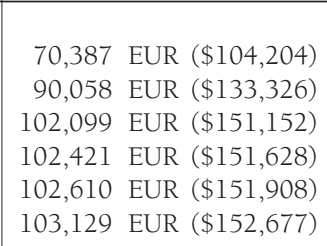 & $\begin{array}{l}1.182 \\
1.655 \\
1.838 \\
2.049 \\
2.105 \\
2.097\end{array}$ & $\begin{array}{c}\text { Reference } \\
41,561 \text { EUR }(\$ 61,529) \\
48,334 \text { EUR }(\$ 71,556) \\
36,926 \text { EUR }(\$ 54,668) \\
34,922 \text { EUR }(\$ 51,700) \\
35,760 \text { EUR }(\$ 52,941)\end{array}$ & $\begin{array}{c}\text { NA } \\
41,561 \text { EUR }(\$ 61,529) \\
65,869 \text { EUR }(\$ 97,516) \\
1,523 \text { EUR }(\$ 2,254) \\
3,423 \text { EUR }(\$ 5,068) \\
\text { Dominated }\end{array}$ \\
\hline $\begin{array}{l}\text { Bansback et al., } 2004 \\
\left(\text { ACR20 analysis) }{ }^{26}\right.\end{array}$ & $\begin{array}{c}\text { DMARD } \\
\text { Etanercept } \\
\text { MTX + adalimumab } \\
\text { MTX + infliximab } \\
\text { adalimumab } \\
\text { MTX + etanercept }\end{array}$ & $\begin{aligned} 68,757 & \text { EUR }(\$ 101,791) \\
112,351 & \text { EUR }(\$ 166,329) \\
114,462 & \text { EUR }(\$ 169,454) \\
114,732 & \text { EUR }(\$ 169,854) \\
116,442 & \text { EUR }(\$ 172,386) \\
133,590 & \text { EUR }(\$ 197,772)\end{aligned}$ & $\begin{array}{l}1.704 \\
2.730 \\
2.742 \\
2.412 \\
2.432 \\
2.952\end{array}$ & $\begin{array}{c}\text { Reference } \\
42,480 \text { EUR }(\$ 55,383) \\
44,019 \text { EUR }(\$ 57,388) \\
64,936 \text { EUR }(\$ 84,658) \\
65,501 \text { EUR }(\$ 85,395) \\
51,974 \text { EUR }(\$ 67,760)\end{array}$ & $\begin{array}{l}\text { NA } \\
27,099 \text { EUR }(\$ 35,330) \\
22,444 \text { EUR }(\$ 29,261) \\
22,001 \text { EUR }(\$ 28,683) \\
36,627 \text { EUR }(\$ 47,751) \\
36,576 \text { EUR }(\$ 47,685)\end{array}$ \\
\hline
\end{tabular}

* Costs are reported in the year of analysis; (costs are adjusted to 2004 U.S. dollars as shown in parentheses).

+ ICERs are calculated by comparing each comparator to the reference.

$\$$ ICERs are calculated by comparing each comparator to the next best nondominated agent.

ACR20 = American College of Rheumatology 20\% response criteria; ACR50=American College of Rheumatology 50\% response criteria; DMARDs=disease-modifying antirheumatic drugs; ICER=incremental cost-effectiveness ratio; MTX=methotrexate; N/A=not applicable;

QALY= quality-adjusted life-year.

Currency: $\mathcal{E}=$ British pound; EUR=Euro; SEK=Swedish krona. 
per QALY gained (\$51,700, 2004 USD). Infliximab plus methotrexate had the highest incremental cost-effectiveness ratio at 48,334 EUR per QALY gained (\$71,556, 2004 USD) (Table 7). The authors concluded that biologics were cost effective based on acceptability thresholds established in other European countries.

Brennan et al. (Table 6) examined the cost-effectiveness of etanercept monotherapy compared with current care in the United Kingdom in accordance with the BSR guidelines. Patients who entered the model had failed at least 2 DMARDs. ${ }^{24}$ The model compared patients who continued on a protocol of either a series of traditional DMARDs or etanercept monotherapy (followed by the above DMARD series in case of adverse effects or lack of efficacy). Using etanercept as a monotherapy after failures with traditional DMARDs was more costly (Table 7) but more efficacious, and was associated with a favorable costeffectiveness profile ( $£ 16,330$ per QALY gained $[\$ 29,433$ in 2004 USD] compared with treatment using a series of DMARDs). The results were relatively insensitive to changes in key parameters, with the ICERs ranging between $£ 14,000$ and $£ 21,000$ per QALY gained $(\$ 25,233$ and $\$ 37,850,2004$ USD, respectively).

\section{Discussion}

The introduction of biologic DMARDs for the management of RA poses several challenges for health care decision makers, especially in an era when drug expenditures continue to rise and cost containment is common. First, at an average annual drug cost of $\$ 17,000$ to $\$ 18,000$, biologic DMARDs are much more costly than traditional DMARDs. The annual cost of methotrexate therapy is approximately $\$ 200$ (assuming $7.5 \mathrm{mg}$ per week). Moreover, the studies reviewed have consistently shown that the additional costs of biologics are not completely offset by preventing future disability; hence, the clinical benefits of biologic therapy are likely to come with additional costs. These facts cause payers to be concerned about the value for money obtained from the use of biologic therapy. In the process of trying to determine formulary placement of these expensive specialty drugs, benefit designers also need to consider member access and cost sharing.

Second, the demand for biologics from physicians and patients may increase with more data from RCTs indicating that biologics improve ACR response and decrease disability. Managed care organizations must balance the evidence on safety, efficacy, effectiveness, and cost to assess the economic value of biologic therapy. Well-conducted CEAs are potentially helpful here.

The studies reviewed here suggest that the additional benefits of biologics after failing traditional DMARDs may be worth the additional cost compared with DMARD continuation, based on the commonly cited thresholds used in the different countries. These thresholds, also referred to as ICERs, represent the additional amount of money that payers will spend to gain 1 additional QALY (i.e., a year of perfect health) compared with the current gold standard or best therapy option. While no threshold formally exists in the United States, historically an ICER of $<\$ 50,000$ per QALY gained has been cited as a good value for the additional spending. In other words, the drug can be considered cost effective if the ICER is $\leq \$ 50,000$. However, an ICER approaching $\$ 100,000$ per QALY gained has also been used to justify additional drug spending. ${ }^{28}$

The ICERs reported in the studies in our review are within or below this range, even after adjusting for inflation and differences in currencies. In the United States, the adjusted ICER from Wong et al. ${ }^{21}$ was $\$ 11,670$ per QALY gained for infliximab plus methotrexate compared with methotrexate alone (Table 7). In the United Kingdom, these adjusted ICERs ranged from $\$ 29,433$ (for etanercept compared with traditional DMARDs) to $\$ 48,710$ (for infliximab plus methotrexate compared with methotrexate alone) (Table 7). Studies from the Swedish setting reported adjusted ICERs ranging from $\$ 3,500$ (for infliximab plus methotrexate compared with methotrexate alone) to $\$ 85,395$ (for adalimumab compared with DMARDs). Despite the dissimilarity in their methodologies, these studies consistently reported ICERs within the range where payers may accept additional spending for these agents.

Pharmacoeconomic models may aid decision making in several ways. First, primary collection of data on costs and utilization in an RCT is often impractical; models can overcome this limitation because they can synthesize information from disparate sources. Second, a drug is often compared with placebo in an RCT, but decision makers need to know how the drug compares with standard therapy. Third, models can be used to project the long-term costs and consequences for a chronic condition such as RA in the absence of actual data from RCTs. Lastly, the results from a well-designed model can be presented in a useful metric such as cost per QALY gained, so that therapies can be compared within RA and across other conditions.

Policy makers using these models to make decisions will need to inspect how the study was conducted, to verify the face-validity of key assumptions and to determine whether the model was framed in a way that answered the relevant questions. Several questions need to be addressed before applying the results to the payer's population.

First, are the metrics reported from these studies useful? Modeling the effective measure as a function of ACR response is practical because this outcome is often reported in clinical trials. For example, the 2 studies by Choi et al. reported the incremental cost per additional patient with ACR response. . $^{18,19}$ Response rate is useful when decision makers are only concerned with comparing relative efficacies of different agents. However, this metric has limited application for formulary decision making in the context of cost-effectiveness because the results cannot be easily compared with those of other economic 
evaluations in RA or even in other medical conditions.

Without a predefined maximum cost that purchasers will pay to achieve additional ACR response, the economic value of biologics is undetermined. Patients who achieved ACR20 outcomes can still suffer from residual symptoms (tender and swollen joints); these patients may continue to endure up to $80 \%$ of their original symptoms. Therefore, decision makers should also ask the following important question: Are the partially treated symptoms worth the additional cost to alleviate them? Alternatively, the U.S. Public Health Service Panel on Cost-effectiveness in Health and Medicine has recommended reporting cost per QALY gained because comparisons across different medical conditions and interventions would be easier. ${ }^{29}$ QALYs capture the composite effect of treatment on mortality (or survival) and morbidity. For a chronic condition such as RA, emphasis should also be placed on the long-term progression of disability, how biologics can delay disability, and how this benefit translates to QALYs. Models that accounted for these factors (Kobelt et al., ${ }^{23}$ Brennan et al. ${ }^{24}$ and Bansback et al. ${ }^{26}$ ) scored highly on the QHES instrument and should be given greater weight during formulary decision or other review processes.

Second, in the absence of data, how do the models relate treatment to long-term consequences? Because RCTs involving RA are short in duration, the need for modeling to understand the long-term clinical benefits from biologics is inevitable. However, projecting these benefits beyond the clinical trial period requires adding assumptions to the pharmacoeconomic model that necessitate careful scrutiny. Kobelt et al. ${ }^{23}$ and Wong et al. ${ }^{21}$ projected clinical benefits for up to 10 years based on RCTs of only 1 year's duration that included outcomes for all patients including those that discontinued therapy. The assumption about when clinical benefit from biologics will diminish is essential for assessing the value of biologics. Wong et al. ${ }^{21}$ assumed that the clinical benefit from infliximab plus methotrexate would be diminished by one third at 2 years, three fourths by 5 years, and almost completely by 10 years. This base-case scenario was associated with an ICER of $\$ 9,100$ per QALY gained ( $\$ 11,670,2004$ USD). However, when it was assumed that the clinical benefit was lost by 5 years, the corresponding ICER increased to $\$ 47,000$ per QALY gained $(\$ 60,274,2004$ USD). In the most extreme scenario of assuming that all of the benefit is lost immediately after stopping infliximab, the ICER increased to $\$ 93,000$ per QALY gained $(\$ 119,265$, 2004 USD).

This example illustrates that the cost-utility is very sensitive to the assumption of when the clinical benefit would diminish, and the resulting policy decision could change depending on that assumption. Kobelt et al. ${ }^{23}$ modeled costs and benefits beyond the first year by applying the progression of disability (i.e., HAQ) using epidemiological data. Contrary to what Wong et al. ${ }^{21}$ observed, the ICER from a scenario when clinical benefit was lost at discontinuation after 1 year of treatment was not substantially different from the base case. Brennan et al. ${ }^{24}$ constructed a conservative lifetime model by assuming that upon withdrawal of etanercept, disability as measured by HAQ score would immediately worsen by exactly the amount equivalent to the initial improvement. The resulting ICER was favorable at $£ 16,330$ per QALY gained $(\$ 29,433,2004$ USD) even with such a conservative assumption. Likewise, Bansback et al. ${ }^{26}$ also applied this same conservative assumption in their base-case model.

Third, to what should the cost-effectiveness of biologics be compared? Although most studies used methotrexate as the reference for comparison, other comparators varied. Kobelt et al. ${ }^{25}$ calculated the cost-effectiveness ratio based on change to baseline costs and utilities rather than a direct comparison to another RA treatment. Brennan et al..$^{24}$ presented a comparison of treatment sequences rather than a pure comparison of one drug versus another. In the management of RA, patients who do not respond to or who cannot tolerate a particular agent will likely switch to alternative agents; therefore, a comparison of competing treatment strategies that accounts for switching and withdrawal would be useful. Likewise, Bansback et al. ${ }^{26}$ presented a model of treatment sequences that may have greater appeal to decision makers as it reflects more realistic utilization of biologics and DMARDs and treatment pattern. In the models by Bennan et al. ${ }^{24}$ and Bansback et al. ${ }^{26}$ patients who do not respond to or cannot tolerate biologics are switched to a traditional DMARD.

Last, how does one differentiate between biologics in value? It will be natural for decision makers to seek the answer to this question in order to guide drug benefit design; however, evidence is lacking. Chiou et al. ${ }^{22}$ was the only study that assessed this relative cost-effectiveness. These investigators maintained that patients enrolled in each of the source RCTs were similar; hence, the efficacies from different studies were applied into their model without any adjustment. However, differences in important characteristics, such as disease duration, disability, and methotrexate response, could influence study outcomes. Therefore, clinical trials with head-to-head comparisons of biologics are needed to validate the relative benefits. Bansback et al. ${ }^{26}$ accounted for these differences by adjusting for the placebo rates in each trial, but they did not compare one biologic with another. Additional research is needed to differentiate among the biologic DMARDs.

The National Institute for Health and Clinical Excellence (NICE) conducted an independent appraisal of the cost-effectiveness of adalimumab, etanercept, and infliximab and posted preliminary recommendations in early 2006. ${ }^{13}$ Five models were submitted to NICE for review: 1 from each of the manufacturers of the 3 anti-TNF- $\alpha$ agents, 1 from the BSR, and 1 from the Assessment Group. In general, models sponsored by the manufacturers reported lower ICERs compared with the Assessment Group's model. Key findings from the Assessment 
Group's model were that (1) using anti-TNF- $\alpha$ as a first-line treatment is not cost effective (ICER $>£ 100,000$ per QALY gained) and (2) the assumptions relating to HAQ progression have a significant impact on the cost-effectiveness estimates. If the model assumed no progression of disease while responding to treatment (i.e., optimistic scenario), the ICERs (versus no biologic treatment) were $£ 30,000$ per QALY gained for etanercept, $£ 58,000$ per QALY gained for adalimumab, and $£ 55,000$ per QALY gained for infliximab. If disease progression was assumed to occur during biologic treatment (i.e., the conservative basecase scenario), the ICERs (versus no biologic treatment) were $£ 88,300$ per QALY gained for etanercept.

After considering all the economic evidence, the NICE Appraisal Committee concluded that "some patients with severe active disease who have failed to respond to at least 2 trials of DMARDs could be identified and managed cost effectively using 1 of the 3 TNF- $\alpha$ inhibitors. ${ }^{.13}$ Therefore, the committee did not recommend use of a TNF- $\alpha$ inhibitor in early stages of RA. Furthermore, treatment should be discontinued if response is not maintained, defined as clinical deterioration (i.e., increase of DAS28 score by more than 0.6) at consecutive assessments. The findings from the studies in our review support these preliminary recommendations of the NICE Appraisal committee (i.e., patients should have failed traditional DMARDs prior to use of a TNF- $\alpha$ inhibitor.) In addition, the committee appeared to support a conservative approach that analytic models should show the loss of clinical benefits at treatment withdrawal (i.e., recurrence of disability) rather than assume that benefits can be extended beyond discontinuation.

In addition to our qualitative review of these studies, we found that reporting scores from the QHES instrument can be useful to decision makers, particularly those with limited experience with reviewing pharmacoeconomic data, as a way to differentiate one study from another. Ofman and colleagues reported that "experts" in health economics considered the QHES instrument as moderately valuable, but $54 \%$ would still recommend it to others. ${ }^{16}$ On a scale of 1 ("not valuable at all") to 5 ("extremely valuable"), these experts rated the tool with a mean of $3.6( \pm 1.0)$. More importantly, Ofman and colleagues also reported that among those not considering themselves as experts in evaluating health economic analyses, $76 \%$ responded that they would use this tool. In settings where economic evaluations are considered when decisions about resource allocation are made, a tool such as the QHES can be useful.

\section{Limitations}

Four of the 8 economic evaluations reviewed were sponsored by manufacturers of TNF- $\alpha$ inhibitors, and 1 of the 8 studies was sponsored by a manufacturer and not indexed by MEDLINE. Bell and colleagues noted that published cost-effectiveness studies tend to report favorable incremental cost-effectiveness ratios. ${ }^{30}$ Furthermore, Bell et al. found studies funded by industry to be more likely to report ratios below $\$ 20,000, \$ 50,000$, and $\$ 100,000$ per QALY gained. However, studies of higher methodological quality and those conducted in Europe or the United States were less likely to report ratios below $\$ 20,000$ per QALY gained. These observations suggest that decision makers need to consider study sponsorship and inspect such studies more critically for any potential biases. However, industry sponsorship does not necessarily discredit the findings from such studies.

These models relied on efficacy data from source clinical studies in which the patients had failed at least 1 traditional DMARD. Only 3 of the 8 models defined failure to respond to traditional DMARDs as failing at least 2 traditional DMARDs, of which 1 has to be methotrexate (Table 2). ${ }^{24-26}$ This definition of failure is consistent with the recommendation from the BSR guidelines to determine when patients become eligible for biologic therapies. ${ }^{4}$ The 3 studies that evaluated cost-effectiveness of infliximab (in combination with methotrexate) focused on patients with inadequate response as methotrexate resistant but not necessarily having failed 2 DMARDs. ${ }^{19,21,23}$ Arguably, these patients may respond to other less costly traditional DMARD before considering biologic therapies.

A gap exists between clinical practice guidelines and formal indications approved by the U.S. Food and Drug Administration. According to the current prescribing information (Table 1), etanercept and adalimumab can be initiated in combination with methotrexate or used alone. However, patients are rarely prescribed biologics without having tried at least 1 and usually 2 or more traditional DMARDs in the real-world practice setting

The cost-effectiveness literature assessed the use of biologic therapies across a range of clinical circumstances from multiple treatment failures with DMARDs to 1 study that involved DMARD-naive patients. The resulting economic outcomes for these diverse clinical scenarios are consistent with the amount paid for other therapeutic interventions. In a circumstance where only specific clinical situations meet cost-effectiveness guidelines, then a narrowed therapeutic use could be defined. However, we found no such limitation in the pharmacoeconomic literature, and the cost-effectiveness literature has not yet addressed step therapy with DMARDs followed by biologics.

\section{Conclusions}

Biologic therapies are more costly compared with traditional DMARDs but produce more QALYs. Despite differences in design and assumptions, published economic models consistently reported ICERs $<\$ 50,000$ per QALY gained for biologics compared with traditional DMARDs when used among RA patients who have become resistant to DMARDs, although sensitivity analyses reported ICERs of $>\$ 100,000$. This implies that the value of biologics is comparable with that of other wellaccepted medical interventions. Nonetheless, the formulary and policy decision makers will ultimately have to judge whether the additional expenditure justifies the clinical gain because no 
maximum cost has been defined. Although models can be used to inform decisions, they must be interpreted and applied carefully. Specifically, the assumption that clinical benefit will persist after biologics are discontinued needs to be validated in order to substantiate the long-term economic value of biologics. More research is also needed to determine the relative economic value of the various biologic agents for specific therapeutic indications.

\section{ACKNOWLEDGMENTS}

The authors would like to thank Robert A. Charles, PharmD, MS, for abstracting the data from the literature.

\section{DISCLOSURES}

Funding for this study was provided by Amgen, Inc. and was obtained by author Robert W. Dubois. The authors disclose that funding for this research was restricted and that the sponsor was involved with reviewing, editing, and approving the manuscript. Author Chiun-Fang Chiou is employed by Amgen, Inc., and is an Amgen stockholder; he also discloses that he is an author of one of the studies in this subject review. Authors Quan V. Doan and Dubois disclose no potential bias or conflicts of interest relating to this article.

Doan served as principal author of the study. Study concept and design were contributed by all authors. Data collection was the work of Doan; data interpretation was the work of all authors. Writing of the manuscript and its revision were primarily the work of Doan, with input from Dubois and Chiou.

\section{REFERENCES}

1. Silman AJ, Pearson JE. Epidemiology and genetics of rheumatoid arthritis. Arthritis Res. 2002;(4 suppl 3):S265-S272.

2. Pugner KM, Scott DI, Holmes JW, Hieke K. The costs of rheumatoid arthritis: an international long-term view. Semin Arthritis Rheum. 2000;29(5):305-20.

3. American College of Rheumatology Subcommittee on Rheumatoid Arthritis Guidelines. Guidelines for the management of rheumatoid arthritis: 2002 update. Arthritis Rheum. 2002;46(2):328-46.

4. Ledingham J, Deighton C. Update on the British Society for Rheumatology guidelines for prescribing TNF alpha blockers in adults with rheumatoid arthritis (update of previous guidelines of April 2001). Rheumatology. (Oxford) 2005;44(2):157-63

5. Bathon JM, Martin RW, Fleischmann RM, et al. A comparison of etanercept and methotrexate in patients with early rheumatoid arthritis. N Engl J Med. 2000;343(22):1586-93.

6. Weinblatt ME, Kremer JM, Bankhurst AD, et al. A trial of etanercept, a recombinant tumor necrosis factor receptor: Fc fusion protein, in patients with rheumatoid arthritis receiving methotrexate. N Engl J Med. 1999;340(4):253-59.

7. Klareskog L, van der Heijde D, de Jager JP, et al. Therapeutic effect of the combination of etanercept and methotrexate compared with each treatment alone in patients with rheumatoid arthritis: double-blind randomised controlled trial. Lancet. 2004;363(9410):675-81.

8. Smolen JS, van der Heijde DM, St Clair EW, et al. Predictors of joint damage in patients with early rheumatoid arthritis treated with high-dose methotrexate with or without concomitant infliximab: results from the ASPIRE trial. Arthritis Rheum. 2006;54(3):702-10.

9. Bansback NJ, Regier DA, Ara R, et al. An overview of economic evaluations for drugs used in rheumatoid arthritis: focus on tumour necrosis factor-alpha antagonists. Drugs. 2005;65(4):473-96.

10. Nurmohamed MT, Dijkmans BA. Efficacy, tolerability and cost effectiveness of disease-modifying antirheumatic drugs and biologic agents in rheumatoid arthritis. Drugs. 2005;65(5):661-94.

11. Lyseng-Williamson KA, Foster RH. Infliximab: a pharmacoeconomic review of its use in rheumatoid arthritis. Pharmacoeconomics. 2004;22(2): 107-32.
12. Lyseng-Williamson KA, Plosker GL. Etanercept: a pharmacoeconomic review of its use in rheumatoid arthritis. Pharmacoeconomics. 2004;22(16): 1071-95.

13. National Institute for Health and Clinical Excellence. Adalimumab, etanercept and infliximab for the treatment of rhematoid arthritis (appraisal document). March 7, 2006. Available at: http://www.nice.org.uk/page.aspx?o=291165. Accessed April 10, 2006.

14. U.S. Department of Labor. Bureau of Labor Statistics. Consumer Price Indexes. Available at: http://www.bls.gov/CPI. Accessed December 13, 2005.

15. Chiou CF, Hay JW, Wallace JF, et al. Development and validation of a grading system for the quality of cost-effectiveness studies. Med Care. 2003;41(1):32-44

16. Ofman JJ, Sullivan SD, Neumann PJ, et al. Examining the value and quality of health economic analyses: implications of utilizing the QHES.J Manag Care Pharm. 2003;9(1):53-61.

17. Felson DT, Anderson JJ, Boers M, et al. American College of Rheumatology. Preliminary definition of improvement in rheumatoid arthritis. Arthritis Rheum. 1995;38(6):727-35.

18. Choi HK, Seeger JD, Kuntz KM. A cost effectiveness analysis of treatment options for methotrexate-naive rheumatoid arthritis. J Rheumatol. 2002; 29(6):1156-65.

19. Choi HK, Seeger JD, Kuntz KM. A cost-effectiveness analysis of treatment options for patients with methotrexate-resistant rheumatoid arthritis. Arthritis Rheum. 2000;43(10):2316-27.

20. Fries JF, Spitz P, Kraines RG, Holman HR. Measurement of patient outcome in arthritis. Arthritis Rheum.1980;23(2):137-45.

21. Wong JB, Singh G, Kavanaugh A. Estimating the cost-effectiveness of 54 weeks of infliximab for rheumatoid arthritis. Am J Med. 2002;113(5):400-08.

22. Chiou CF, Choi J, Reyes CM. Cost-effectiveness of biological treatments for rheumatoid arthritis. Expert Rev Pharmacoeconomics Outcomes. 2004;4(3): 307-15.

23. Kobelt G, Jonsson L, Young A, Eberhardt K. The cost-effectiveness of infliximab (Remicade) in the treatment of rheumatoid arthritis in Sweden and the United Kingdom based on the ATTRACT study. Rheumatology (Oxford). 2003;42(2):326-35.

24. Brennan A, Bansback N, Reynolds A, Conway P. Modelling the cost-effectiveness of etanercept in adults with rheumatoid arthritis in the UK. Rheumatology (Oxford). 2004;43(1):62-72

25. Kobelt G, Eberhardt K, Geborek P. TNF inhibitors in the treatment of rheumatoid arthritis in clinical practice: costs and outcomes in a follow-up study of patients with RA treated with etanercept or infliximab in southern Sweden. Ann Rheum Dis. 2004;63(1):4-10.

26. Bansback NJ, Brennan A, Ghatnekar O. Cost-effectiveness of adalimumab in the treatment of patients with moderate to severe rheumatoid arthritis in Sweden. Ann Rheum Dis. 2005;64(7):995-1002.

27. Young A, Dixey J, Cox N, et al. How does functional disability in early rheumatoid arthritis (RA) affect patients and their lives? Results from a 5-year follow-up in 732 patients from the Early RA study. Rheumatology. 2000;39(6): 603-11.

28. Azimi NA, Welch HG. The effectiveness of cost-effectiveness analysis in containing costs. J Gen Intern Med. 1998;13(10):664-69.

29. Gold MR, Siegel JE, Russell LB, Weinstein MC, editors. Cost-Effectiveness in Health and Medicine: The Report of the Panel on Cost-Effectiveness in Health and Medicine. New York, NY: Oxford University Press; 1996.

30. Bell CM, Urbach DR, Ray JG, et al. Bias in published cost effectiveness studies: systematic review. BMJ. 2006; 332(7543):699-703 